\title{
Exploring the functional interaction between POSH and ALIX and the relevance to HIV-I release
}

\author{
Jörg Votteler ${ }^{1}$, Elena Iavnilovitch ${ }^{2}$, Orit Fingrut ${ }^{2}$, Vivian Shemesh ${ }^{2}$, \\ Daniel Taglicht ${ }^{2}$, Omri Erez ${ }^{2}$, Stefan Sörgel ${ }^{1}$, Torsten Walther ${ }^{3}$, \\ Norbert Bannert ${ }^{4}$, Ulrich Schubert*1,3 and Yuval Reiss*2
}

\begin{abstract}
Address: ${ }^{1}$ Institute of Virology, Friedrich-Alexander University, Erlangen, Germany, ${ }^{2}$ Proteologics Ltd, Rehovot, Israel, ${ }^{3}$ ViroLogik GmbH, Erlangen, Germany and ${ }^{4}$ Robert Koch Institute, Berlin, Germany

Email: Jörg Votteler - Joerg.Votteler@viro.med.uni-erlangen.de; Elena Iavnilovitch - elena@proteologics.com;

Orit Fingrut - orit@proteologics.com; Vivian Shemesh - vivian@proteologics.com; Daniel Taglicht - danny@proteologics.com;

Omri Erez - omri@ proteologics.com; Stefan Sörgel - stefan.soergel@viro.med.uni-erlangen.de; Torsten Walther - t.walther@virologik.com;

Norbert Bannert - BannertN@rki.de; Ulrich Schubert* - ulrich.schubert@viro.med.uni-erlangen.de; Yuval Reiss* - yuval58@netvision.net.il

* Corresponding authors
\end{abstract}

Published: 24 April 2009

BMC Biochemistry 2009, 10:12 doi:10.1186/1471-2091-10-12
Received: 16 December 2008

Accepted: 24 April 2009

This article is available from: http://www.biomedcentral.com//47/-2091//0/12

(C) 2009 Votteler et al; licensee BioMed Central Ltd.

This is an Open Access article distributed under the terms of the Creative Commons Attribution License (http://creativecommons.org/licenses/by/2.0), which permits unrestricted use, distribution, and reproduction in any medium, provided the original work is properly cited.

\begin{abstract}
Background: The ALG2-interacting protein X (ALIX)/AIPI is an adaptor protein with multiple functions in intracellular protein trafficking that plays a central role in the biogenesis of enveloped viruses. The ubiquitin E3-ligase POSH (plenty of SH3) augments HIV-I egress by facilitating the transport of Gag to the cell membrane. Recently, it was reported, that POSH interacts with ALIX and thereby enhances ALIX mediated phenotypes in Drosophila.
\end{abstract}

Results: In this study we identified ALIX as a POSH ubiquitination substrate in human cells: POSH induces the ubiquitination of ALIX that is modified on several lysine residues in vivo and in vitro. This ubiquitination does not destabilize ALIX, suggesting a regulatory function. As it is well established that ALIX rescues virus release of L-domain mutant HIV-I, HIV-I $\Delta_{\text {PTAP }}$, we demonstrated that wild type $\mathrm{POSH}$, but not an ubiquitination inactive RING finger mutant (POSHVI4A), substantially enhances ALIX-mediated release of infectious virions derived from HIV-I $\Delta_{\text {PTAP }} L$-domain mutant (YPX $\mathrm{L}$-dependent HIV-I). In further agreement with the idea of a cooperative function of POSH and ALIX, mutating the $\mathrm{YPX}_{\mathrm{n}} \mathrm{L}$-ALIX binding site in Gag completely abrogated augmentation of virus release by overexpression of POSH. However, the effect of the POSH-mediated ubiquitination appears to be auxiliary, but not necessary, as silencing of POSH by RNAi does not disturb ALIX-augmentation of virus release.

Conclusion: Thus, the cumulative results identified ALIX as an ubiquitination substrate of POSH and indicate that POSH and ALIX cooperate to facilitate efficient virus release. However, while ALIX is obligatory for the release of YPX ${ }_{n} L$-dependent HIV-I, POSH, albeit rate-limiting, may be functionally interchangeable. 


\section{Background}

The release of nascent retrovirus particles requires the deployment of the ESCRT (endosomal sorting complex required for transport) to the site of virus budding at the cell surface [1-4]. ESCRT consists of four sub-complexes (ESCRT0-III) that normally reside on the cytoplasmic leaflet of the membrane of late endosomes where they function in tandem to target endocytosed plasma membrane proteins into mutivesicular bodies (MVBs) en route to lysosomes [5-7]. Recruitment of ESCRT to the site of virus budding is facilitated by interaction of specific ESCRT proteins with short peptide sequences termed late (L-) domains of retroviruses Gag proteins such as the p6 and p9 of human immunodeficiency virus (HIV)-1 and equine infectious anemia virus (EIAV), respectively.

ALIX (ALG2 interacting protein $\mathrm{X}$ ) is a multifunctional protein adaptor that plays a central role in the regulation of intracellular protein trafficking and apoptosis. As an ESCRT-associated regulator of protein trafficking, ALIX plays an essential role in retrovirus release, an activity that is dependent on the interaction between the central Vdomain and the L-domain consensus sequence $\mathrm{YPX}_{\mathrm{n}} \mathrm{L}$ in Gag $[8,9]$. The function of ALIX to enhance virus release requires both the amino proximal Bro-domain that binds the ESCRT-III component CHMP4B as well as the carboxyl terminal proline-rich region (PRR) that interacts with multiple ALIX effectors including the tumor susceptibility gene (Tsg) $101[9,10]$. Tsg101 is a component of the ESCRT-I and is essential for the release of retroviruses like HIV-1 that contain a PTAP L-domain motif $[1,11]$. Based on the fact that ALIX binds both CHMP and Tsg101 and the redundancy of ESCRT-II for HIV-1 release [12], it has been proposed that ALIX facilitates virus budding by recruiting ESCRT-III to ESCRT-I to which the nascent virus initially binds. In agreement with this hypothesis, overexpression of the ALIX V-domain potently inhibits HIV-1 release, a dominant negative function that is reversed by mutations that abolish ALIX-Gag binding [13]. In contrast, preventing ALIX-Gag interaction has only a mild effect on the release of HIV-1 [14], while the ablation of Tsg101-Gag interaction blocks virus release almost completely [4,15-17].

In addition to the binding of HIV-1 p6, ALIX was recently found to bind to nucleocapsid (NC) via its N-terminal Bro-domain in an RNA independent manner [18]. This interaction depends on the zinc finger motif in NC which mediates packaging of genomic RNA into budding virions. Intriguingly, zinc finger mutant viruses exhibited a phenotype similar to PTAP mutants, suggesting a functional link between NC and the L-domain in p6 [18].

The trans-Golgi network (TGN) RING finger protein POSH (Plenty of SH3) is a scaffold protein that acts as an
E3 ligase and as an activator of the JNK pathway (Jun Nterminal kinase), a function that is independent of its ubiquitination activity. Previously it was demonstrated that the ubiquitination activity of POSH is required for the trafficking of HIV-1 Gag from the TGN to the plasma membrane [19]. Subsequent reports implicated the E3 ligase activity of POSH in the degradation of the early endosome sorting factor Hrs (hepatocyte growth factorregulated tyrosine substrate) [20], in the regulation of the Drosophila immune response by mediating degradation of the JNK activator TAK-1 (TGF-beta-activated kinase-1) [21] and in the regulation of calcium homeostasis through spatial control of HERP (homocysteine-inducible endoplasmic reticulum protein) [22].

Recent findings identified ALIX along with ALG-2 as binding proteins of POSH in Drosophila. Thereby, $\mathrm{POSH}$ enhances ALIX mediated phenotypes in transgenic fruit flies [23]. Most intriguingly, these findings provided a clue for a possible molecular mechanism by which POSH regulates virus release in human cells. In the present study, we therefore investigated whether POSH cooperates with ALIX in terms of promoting virus release. We hereby report that ALIX is a POSH ubiquitination substrate. Further, we demonstrate that E3 ligase active POSH substantially enhances ALIX-mediated virus release. However, down-regulation of POSH fails to block ALIX virus promoting activity, indicating that POSH is not obligatory but rather an auxiliary co-factor for ALIX to facilitate virus release.

\section{Results \\ POSH binds to ALIX in human cells}

Previous results demonstrated an interaction between POSH and ALIX in Drosophila. To confirm this interaction in human cells, detergent extracts from HeLa cells transiently co-expressing epitope-tagged POSH and ALIX were subjected to immunoprecipitation of ALIX followed by Western blot analysis. POSH was efficiently co-precipitated by antibodies against ALIX (Figure 1A). Also the RING finger mutant POSHV14A, which is inactive as an E3 ligase and was previously shown to function in a dominant-negative manner [19], was efficiently co-immunoprecipitated using anti-ALIX antibodies (Figure 1A). The amount of ALIX-bound POSH was directly proportional to the amount of expressed POSH. Thus, POSHV14A mutant that expresses at higher levels than wild-type POSH also shows increased binding to ALIX.

To ascertain that POSH binds directly to ALIX rather than through the mediation of another cellular factor, bacterially expressed recombinant POSH and ALIX were incubated in vitro and subsequently immunoprecipitated with antibodies against FLAG-tagged ALIX followed by Western blot analysis with POSH specific antibodies. Consistent 


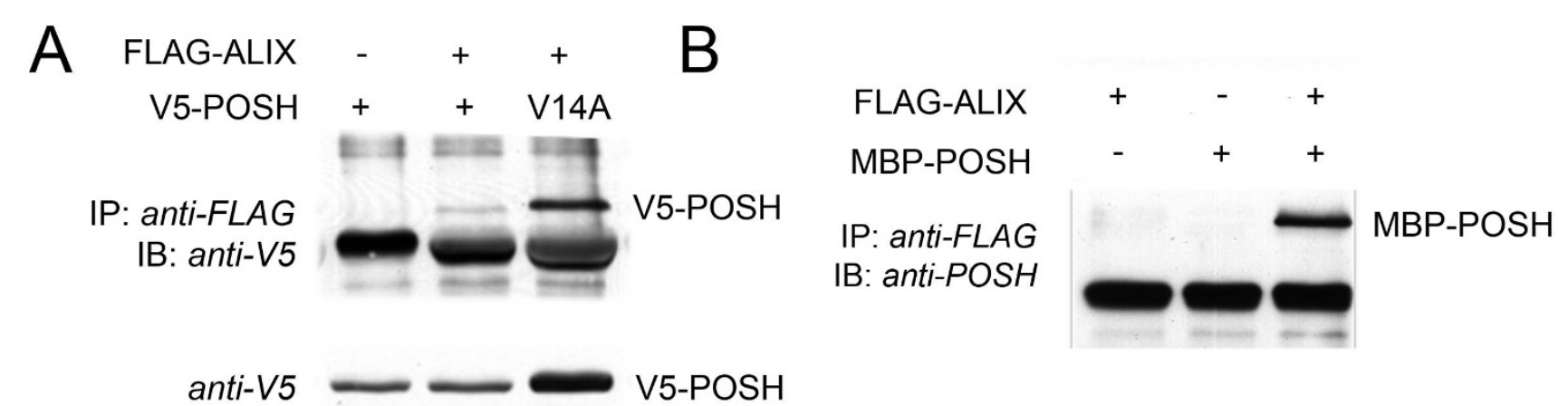

\begin{abstract}
Figure I
POSH and ALIX are interacting proteins. A. Interaction in mammalian cells. Flag-tagged ALIX and V5-tagged POSH-were co-expressed in 293-HEK cells. ALIX immune complexes were isolated from cell detergent extracts by immunoprecipitation with anti-FLAG and analyzed for the presence of POSH by Western blot with anti-V5. B. Direct interaction in vitro. Bacteriallyexpressed POSH (50 ng) and ALIX (50 ng) were incubated in binding buffer as described in Materials and Methods and then subjected to immonoprecipitation with anti-FLAG. Immune complexes were subsequently analyzed for the presence of POSH by Western blot with anti-POSH (PTI).
\end{abstract}

with in vivo data, POSH was efficiently co-precipitated by antibodies against ALIX, indicating that POSH directly interacts with ALIX (Figure 1B).

\section{ALIX is a POSH ubiquitination substrate}

The finding that ALIX associates with POSH prompted us to test whether ALIX is a POSH ubiquitination substrate. To investigate this we employed a HeLa H310A cell line in which the POSH gene is efficiently silenced due to constitutive expression of a POSH specific shRNA [22]. These cells were co-transfected with ALIX, HA-tagged ubiquitin and either RNAi insensitive $w t$ POSH or POSHV14A. Subsequent analysis of immunoprecipitated ALIX by Western blot with anti-HA revealed that POSH, but not POSH ${ }^{\mathrm{V} 14 \mathrm{~A}}$, induced the formation of high molecular weight ALIXubiquitin adducts (Figure 2A). It should be noted that the exogenous overexpression of POSH never exceeds the endogenous POSH levels and that of ALIX increases cellular protein level by approximately 10 -fold (as determined by anti-ALIX, data not shown). Thus it is unlikely that the ubiquitination of ALIX by POSH is due to either nonphysiological E3 levels or substrate concentration that could induce otherwise a non-physiological enzyme-substrate interaction.

To discern whether POSH ubiquitinates ALIX directly or rather, confers regulation of ALIX ubiquitination indirectly, we tested whether ALIX is a POSH ubiquitination substrate in vitro. To this end, bacterially expressed recombinant ALIX and POSH were incubated in the presence of ubiquitin, an E1 ubiquitin activating enzyme, an E2 conjugating enzyme and ATP in an in vitro ubiquitination reaction followed by Western blot analysis of the reaction products with anti-ALIX. The incubation of POSH with
ALIX again produced high molecular ALIX species in an ATP-dependent fashion (Figure 2B). Together, the in vivo and in vitro ubiquitination results established that ALIX is indeed a POSH ubiquitination substrate.

The conjugation of multiple ubiquitin moieties to ALIX together with the fact that this ubiquitination does not induce ALIX degradation suggests a conjugation of either non-canonical poly-ubiquitin chains or multiple monoubiquitin molecules. The best characterized non-canonical protein polyubiquitination is that formed through ubiquitin moieties linked by isopeptide linkages via lysine (K) 63 residue of ubiquitin. This type of polyubiquitin chain formation is strictly dependent on the activity of the heterodimeric E2 Ubc13/Uev1 [24,25]. To gain insight into the type of ubiquitination of ALIX induced by POSH we sought to further characterize the ubiquitination by employing the in vitro ubiquitination assay. To this end, bacterially expressed recombinant ALIX and POSH were incubated in the presence of ubiquitin, an E1 ubiquitin activating enzyme, two different E2 conjugating enzymes (UbcH5c and Ubc13/Uev1) and ATP in an in vitro ubiquitination reaction followed by Western blot analysis of the reaction products with anti-ALIX. The incubation of POSH and ALIX with UbcH5c produced high molecular ALIX species in an ATP-dependent fashion (Figure 2B) while incubation with Ubc13/Uev1 did not although $\mathrm{POSH}$ is active with Ubc13 for ubiquitination of Herp [22]. As UbcH5c does not support formation of K63linked polyubiquitin chains, the production of high molecular weight ALIX species is indicative of either multiple monoubiquitin molecules attached to multiple lysine residues within ALIX, or formation polyubiquitin chains linked by any other internal lysine of ubiqitin 


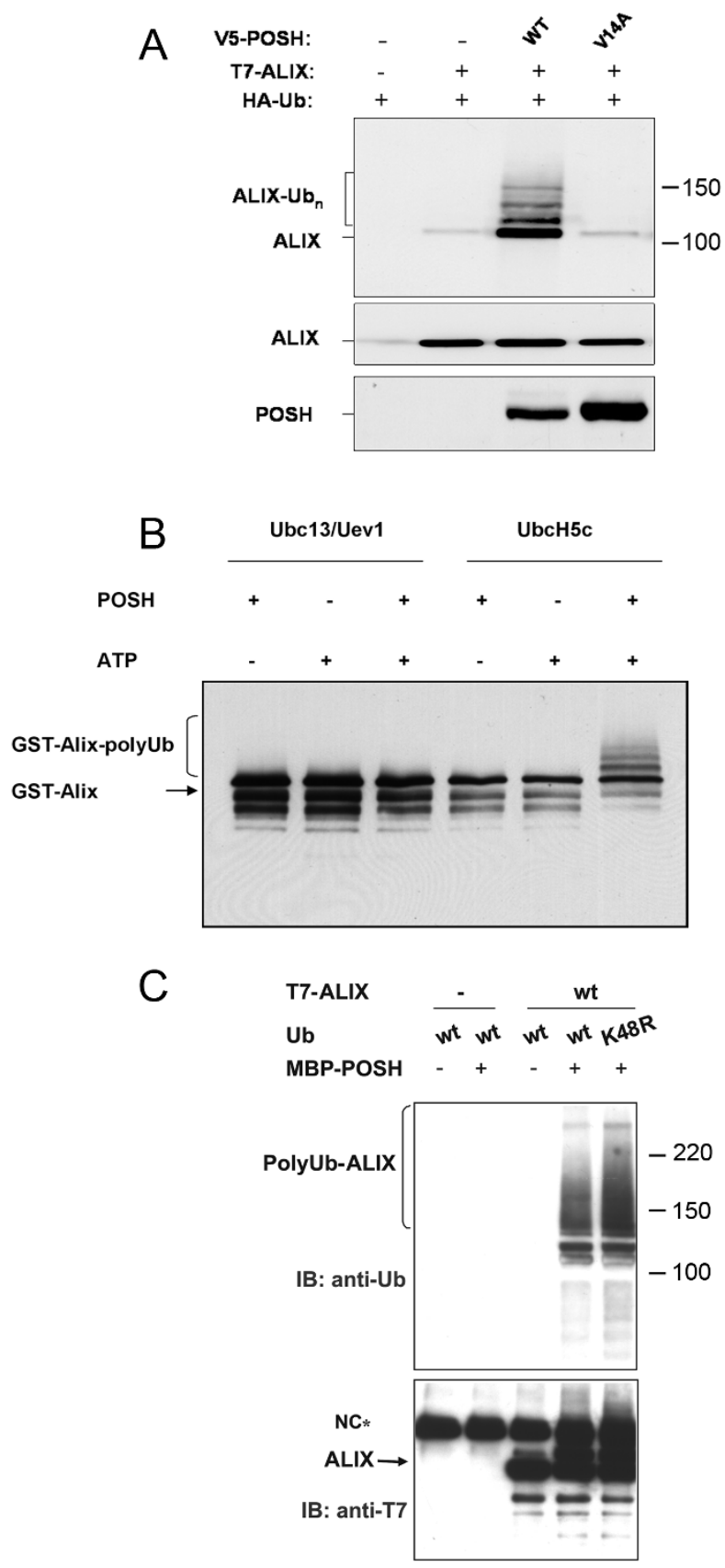

\section{Figure 2}

ALIX is a POSH ubiquitination substrate. A. Overexpression of POSH induces ALIX poly-ubiquitination. Flag-ALIX and V5-POSH were expressed in H310 cells together with HA-ubiquitin. ALIX immune complexes were isolated and ALIX-ubiquitination was detected by Western blot with anti-HA. B. POSH ubiquitinates ALIX in vitro. Bacterially expressed ALIX (50 ng) and POSH (40 ng) were incubated in an in vitro ubiquitination reaction with the indicated Ubc's (E2's) as described in Materials and Methods. ALIX was subsequently isolated by immunoprecipitation with anti-FLAG and analyzed by Western blot with antiFLAG. C. ALIX-linked ubiquitination is independent of K48 residue in ubiquitin. T7-tagged-ALIX was overexpressed in HEK293 cells. ALIX immune complexes were subsequently isolated by immunoprecipitation with anti-T7 and incubated in an in vitro ubiquitination reaction with $\mathrm{POSH}$ and $\mathrm{UbcH} 5 \mathrm{c}$ and with either native ubiquitin or UbK48R as described in Materials and Methods. Following the ubiquitination reaction, ALIX was isolated by immunoprecipitation with anti-FLAG followed by a stringent wash with buffer containing $0.6 \%$ SDS (to disrupt ALIX-POSH interaction and thus ensure detection of ALIX-conjugated ubiquitin only). 
besides K63. Indeed, when a K48R ubiquitin, (where K48 is replaced by arginine), was employed in the in vitro reaction the polyubiquitinated ALIX species formed by POSH and $\mathrm{UbcH} 5 \mathrm{c}$ were indistinguishable from those formed in the presence of native ubiquitin (Figure $2 \mathrm{C}$ ). This result in conjunction with the inactivity of Ubc13/Uev1a indicates that POSH induces either poly-ubiquitin chains linked via any other lysine besides K48 and K63 in ubiquitin, or poly-mono-ubiquitination where single ubiquitin molecules are conjugated to multiple lysine residues of ALIX.

\section{Multiple ubiquitination sites are targeted by $\mathrm{POSH}$}

We next set out to investigate which domain of ALIX is ubiquitinated by POSH. For that reason, truncation mutants of ALIX were co-expressed with POSH and HAtagged ubiquitin in H310A cells and ALIX-ubiquitin adducts were determined by Western blot with anti-HA. The C-terminal PRR of ALIX was the most promising candidate to be targeted by POSH as it was shown to interact with SH3-domains [26]. However, deletion mutants of the last amino acids still were ubiquitinated by POSH (Figure 3). Even when the entire PRR was deleted, POSH still induced the formation of high molecular weight ALIX-ubiquitin adducts (Figure 3), indicating that POSH also binds and ubiquitinates regions outside the PRR. Also a deletion of the N-terminal Bro-domain did not disturb the POSH-ALIX interaction as an N-terminal truncation mutant of ALIX is still ubiquitinated by POSH (Figure 3). Only the central V-domain was not targeted by POSH, either for the reason that it does not contain an ubiquitination site, or that it does not bind to POSH (Figure 3).

\section{POSH enhances ALIX mediated augmentation of virus release}

Recent studies demonstrated that overexpression of ALIX can rescue the production of an $\mathrm{HIV}-1_{\triangle \mathrm{PTAP}}$ mutant virus, that otherwise is severely attenuated due to its L-domain deficiency $[9,14]$. We therefore employed a full-length infectious HIV-1 ${ }_{\mathrm{NL} 4-3}$ molecular clone, in which the PTAP motif was replaced by LIRL without affecting the pol ORF (HIV-1 $\left.{ }_{\triangle \mathrm{PTAP}}[27]\right)$ to explore the function of ALIX in virus biogenesis. Consequently, HeLa SS6 cells were co-transfected with HIV-1 $1_{\triangle \mathrm{PTAP}}$ together with ALIX and POSH. Gag processing and release of infectious virions was determined 24-h post transfection by Western blot and single round infection of TZM-bl cells. The overexpression of POSH alone slightly enhanced both the expression of Gag and the release of virus particles (Figure 4, lane 2), while overexpression of ALIX dramatically stimulated virus release by approximately 10-fold (Figure 4, lane 3) as described previously [9]. However, co-expression of both exogenous POSH and ALIX further amplified virus production up to 25-fold compared to the control (Figure 4, lane 4), indicating that both POSH and ALIX regulate the release of L-domain mutant $\mathrm{HIV}-1$ virions in a synergistic manner.

Measurement of virion associated CA and infectivity as indication of virus release seems to be over-simplistic in this case as it is evident that POSH expression also increased Gag processing (compare intracellular CA in lanes 1 and 2). Hence it is either that POSH contributed to virus release by increasing Gag expression (or stability)

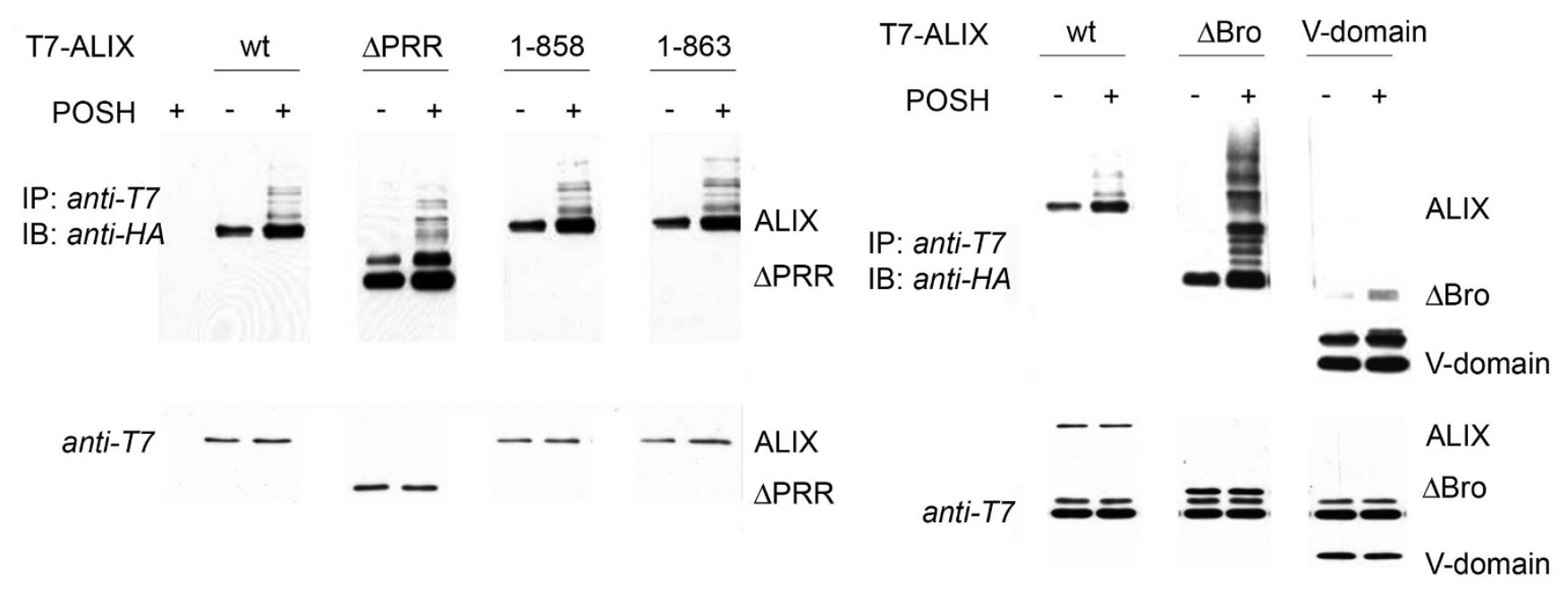

Figure 3

POSH targets multiple sites in ALIX. T7-tagged ALIX derivatives were expressed in HEK-293 cells and then subjected to immunoprecipitation with anti-T7. Isolated ALIX was subsequently incubated in an in vitro ubiquitination reaction and ALIXubiquitin conjugation was analyzed as described in Material and Methods and in the legend to figure 2. 
or that it functioned through a different mechanism. To discern between these possibilities we quantified the Western blot presented in figure $4 \mathrm{~A}$ and subsequently determined the ratios between intracellular CA and virion $\mathrm{CA}$ and total Gag as measurements of Gag processing and virus release, respectively (Figure 4B). According to these measurements, expressed relative to the corresponding ratio in the control, POSH had a minor effect on Gag processing, while ALIX stimulated processing by approximately three-fold (Figure 4B, right panel). POSH in the presence of ALIX did not further stimulate Gag processing. Similarly, POSH minimally affected mutant virus release while ALIX stimulation was over 2.5 -fold (Figure $4 \mathrm{~B}$, left panel). Yet, despite having no effect by itself, in the presence of ALIX, POSH further stimulated virus release up to 4 -fold. Thus, these quantifications indicate that the synergistic contribution of $\mathrm{POSH}$ is through a mechanism independent of the increase of Gag expression.

As we found that POSH ubiquitinates ALIX, we consequently wanted to test whether the enhancing effect of POSH on virus release is dependent on its ubiquitination activity. To this end, the enzymatic inactive POSH ${ }^{\mathrm{V} 14 \mathrm{~A}}$ mutant was tested for the ability to support virus release. Overexpression of POSH ${ }^{\mathrm{V} 14 \mathrm{~A}}$ alone in HeLa SS6 cells did not influence overall virus production (Figure 4A, lane 5) but inhibited relative Gag processing and virus release indicating a dominant negative effect (Figure 4B, lane 5). In contrast to $w t \mathrm{POSH}$, the $\mathrm{POSH}^{\mathrm{V} 14 \mathrm{~A}}$ mutant did not further support ALIX mediated rescue of the HIV-1 $1_{\triangle P T A P}$. Moreover, consistent with a dominant negative effect, overexpression of $\mathrm{POSH}^{\mathrm{V} 14 \mathrm{~A}}$ even slightly suppressed the stimulating effect of ALIX overexpression on virus production (Figure $4 \mathrm{~A}$ and $4 \mathrm{~B}$, lane 6 ).

Next we measured the requirement for POSH for HIV$1_{\triangle \mathrm{PTAP}}$ release at varying ALIX concentrations. To this end H310A cells were co-transfected with HIV- $1_{\triangle \mathrm{PTAP}}$ and increasing amounts of ALIX expression plasmids coexpressed with either empty or POSH expression plasmid. Subsequent determination of virus release (Figure 5) showed that under conditions where ALIX was rate limiting, POSH consistently enhanced mutant virus release by approximately three fold. At higher concentration of ALIX, the enhancing effect of POSH was diminished, most likely due to saturation effects.

To further investigate the cooperative function of POSH and ALIX we tested whether the enhancing effect of POSH on virus release depends on the interaction between ALIX and HIV-1 Gag. Previous studies already indicated that POSH did not directly interact with HIV-1 Gag [19]. Consequently, it can be excluded that the stimulatory effect of POSH on virus release resulted from a direct interaction of POSH with Gag. Yet, abrogating the interaction between
ALIX and Gag should provide further indication whether POSH requires ALIX to stimulate virus production. Therefore, we investigated the ability of POSH to enhance ALIXdependent virus release of HIV-1 $1_{\triangle \mathrm{PTAP}}$ ALIX binding site $\left(\mathrm{YPX}_{\mathrm{n}} \mathrm{L}\right)$ mutant, HIV-1 $1_{\triangle \mathrm{PTAP} / \triangle \mathrm{YP}}$. To this end, POSH was co-expressed together with HIV-1 p6 ALIX binding site variants. The results depicted in figure 6 show that in the presence of the intact ALIX binding site in p6, POSH was able to enhance HIV-1 ${ }_{\triangle \mathrm{PTAP}}$ release (Figure 6, lanes 1 and 2 ). Consistent with previous results [9], the secondary $\triangle$ YP mutation further reduced HIV-1 release and infectivity by an additional 5 -fold (Figure 6 , lanes 1 and 3 ) as this mutation blocks ALIX-Gag interaction and as a result, the ability of ALIX to stimulate virus release. Overexpression of POSH had only slight effect on the release and infectivity of the HIV-1 $1_{\triangle \mathrm{PTAP} / \triangle \mathrm{YP}}$ double mutant virus, indicating that POSH requires the interaction of ALIX and Gag to substantially enhance virus production of a HIV-1 $1_{\triangle \mathrm{PTAP}}$ mutant.

\section{ALIX mediated rescue of HIV-I L-domain mutant occurs independently of $\mathrm{POSH}$}

Thus far, it could be demonstrated that POSH stimulated ALIX-mediated $\mathrm{YPX}_{\mathrm{n}} \mathrm{L}$-dependent virus release and that this effect is depended on its ubiquitination activity. To further elucidate the functional relationship between POSH and ALIX, we investigated the dependence of ALIXmediated virus release on the ubiquitination by POSH. To address this question, endogenous levels of POSH were knocked down by RNAi in order to determine whether ALIX could enhance virus release in the absence of POSH. As shown in figure 7, significant (approximately 70\%) knock down of endogenous levels of POSH by RNAi had no influence on ALIX-mediated rescue of the HIV-1 $1_{\triangle \mathrm{PTAP}}$ mutant, indicating that ALIX retained its activity even when endogenous POSH levels were reduced (Figure 7, compare lanes 1 and 2 to 3 and 4). Similar results were obtained when the POSH deficient H310A HeLa cell line was employed [22] and the ability of ALIX to rescue the release HIV-1 L-domain mutants in these cells was compared to the control cell line H314A (data no shown). Hence, it appears that the virus release enhancing function of ALIX can be stimulated by POSH-mediated ubiquitination, while in contrast down-regulation of POSH does not significantly influence the ALIX activity.

\section{Discussion}

ALIX is a proline rich, multifunctional protein that has been implicated in numerous cellular functions such as regulation of apoptosis and endocytotic protein trafficking $[26,28]$. ALIX was shown to associate with the MVB pathway and thereby being involved in budding of enveloped viruses. More recently it was demonstrated that ALIX as an ESCRT-III associated protein is also involved in the terminal stages of cytokinesis, where it is recruited to the 


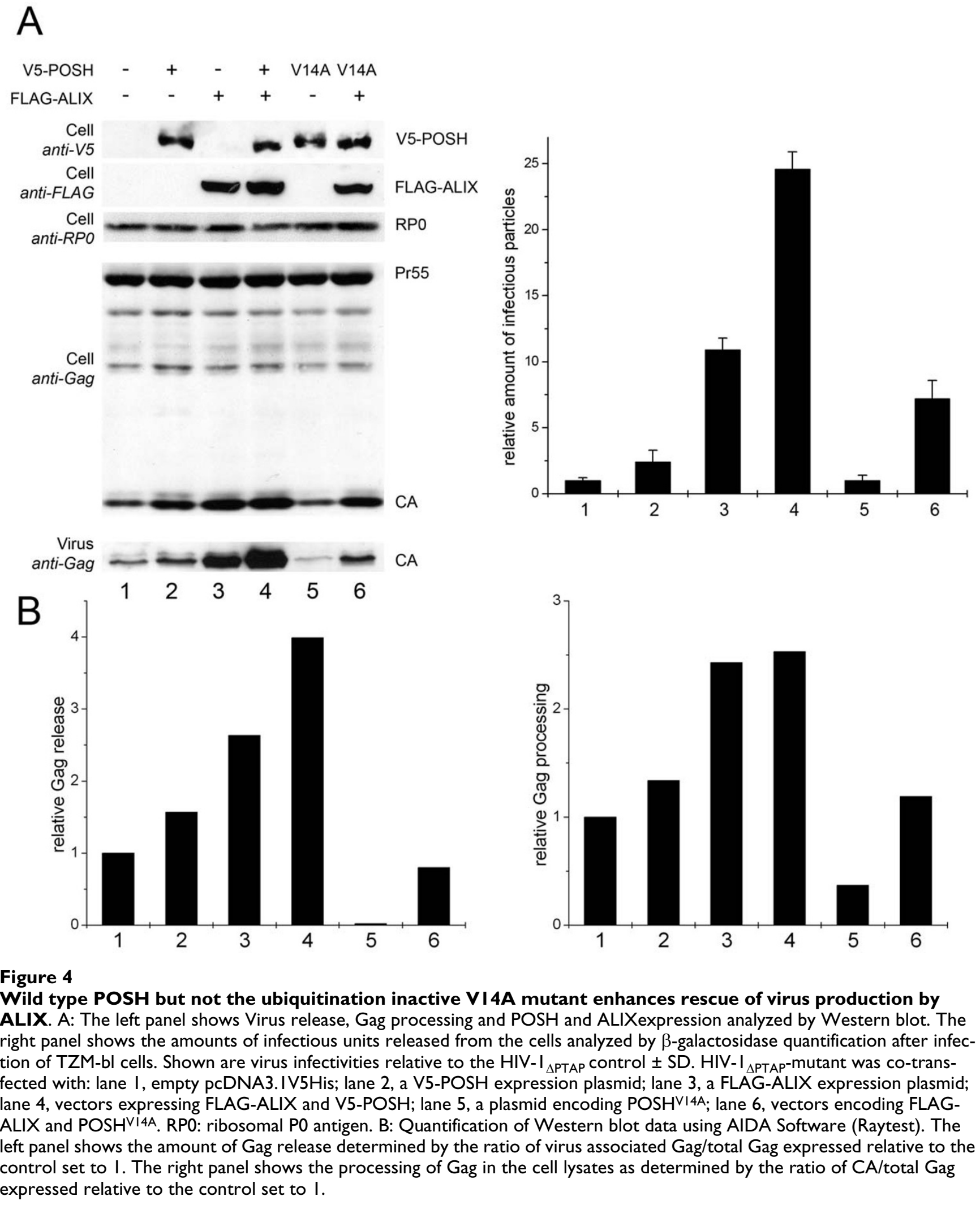




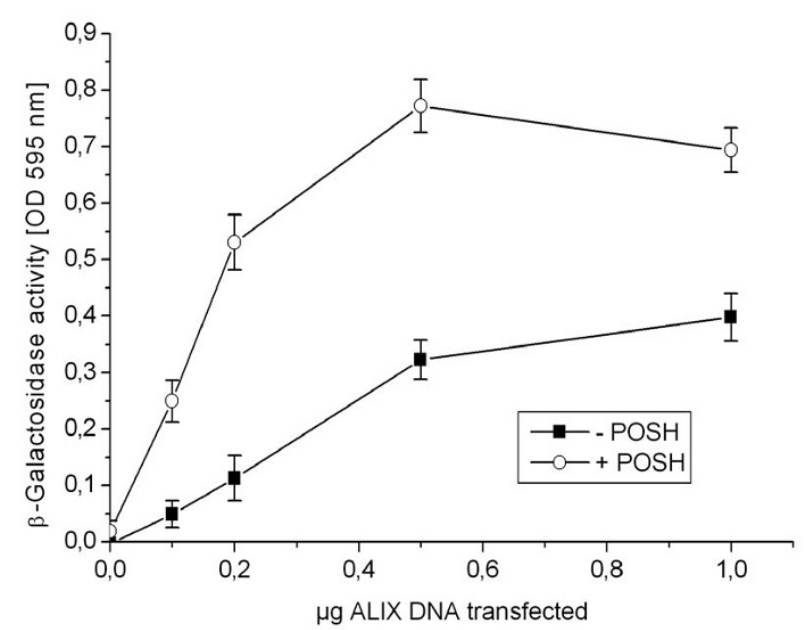

Figure 5

POSH stimulates ALIX mediated virus release. H3IOA cells were co-transfected with $\mathrm{HIV}_{\triangle \mathrm{PTAP}}$, increasing amount of ALIX plasmids, and either a control DNA (black squares) or a POSH expression vector (open circles). The amount of infectious units released from the cells was analyzed by $\beta$-galactosidase quantification after infection of TZM-bl cells.

midbody through binding to Cep55 (centrosome associated protein 55) [29,30]. Biogenesis of intra-endosomal vesicles in MVBs, midbody abscission during cytokinesis and virus budding are topologically equivalent inasmuch as the final step, the pinching off the membrane-stalk, is regulated by the ESCRT.

Due to its multitasking nature, the function of ALIX is tightly regulated by its interaction partners. As already demonstrated earlier by others, ALIX is phosphorylated by the Src thyrosine kinase, which regulates its association with membranes and cytoskeleton as well as its affinity to binding partners SETA/CIN85 and Pyk2 that are involved in receptor downregulation and cell adhesion, respectively [31].

In this study we propose a role for ubiquitination in the regulation of ALIX function. We found, that the TGNassociated scaffolding protein $\mathrm{POSH}$, which exhibits E3ligase activity mediated by its N-terminal RING-domain, ubiquitinates ALIX. Intriguingly, this ubiquitination does not induce proteasomal degradation of ALIX, as there was no reduction in the level of intracellular ALIX upon POSH overexpression. Moreover, as it could be excluded that the ubiquitin chains are linked via K48 of ubiquitin, the noncanonical ubiquitination apparently has a regulatory function. While it could be established that POSH targets multiple lysine residues in ALIX, the detected high molecular ALIX species possibly arise from conjugation of monomeric ubiquitin moieties to several lysine residues. ALIX contains altogether 65 lysine residues from which 33 were predicted by computational analysis to be accessible for ubiquitination (ubiquitin nuggets, http://ubpred.org/). However, the exact nature of this ubiquitination remains obscure. Given that ALIX is ubiquitinated in the presence of $\mathrm{UbcH} 5 \mathrm{c}$ but not in the presence of Ubc13/Uev1 it is likely that POSH either induces multi-ubiquitination on several lysine residues within ALIX or poly-ubiquitin chains linked via ubiquitin lysine residues other than $\mathrm{K} 48$ and $\mathrm{K} 63$ (e. g. K6, K11, K27, K29, and K33) as has been recently described [32]. The functional significance of these types of ubiquitinations on target proteins is still poorly understood.

Besides its numerous functions in regulating cellular pathways, ALIX was described as binding partner of HIV-1 p6 and EIAV p9 thereby being involved in budding and release of these retroviruses $[8,9]$. Previously it was demonstrated that the ubiquitination activity of POSH is required for HIV-1 particle production by facilitating Gag trafficking from the TGN to the cell membrane and thus, stimulates the release HIV-1 particles [19]. The finding that there is a functional interaction between POSH and ALIX prompted us to investigate the importance of this interaction for virus release. Though the specific regulation conferred on ALIX through POSH-dependent ubiquitination is unclear, the data indicates that both proteins somehow cooperate to promote virus release: Overexpression of POSH substantially stimulated the ALIX mediated rescue of an HIV- $1_{\triangle \mathrm{PTAP}}$ mutant, the stimulatory effect of $\mathrm{POSH}$ on virus production was blocked by abrogating Gag-ALIX interaction through introduction of specific mutations within Gag that prevented ALIX binding and the enhancing effect of POSH was completely abolished when its ubiquitination activity was disrupted due to a RING finger mutation $\left(\mathrm{POSH}^{\mathrm{V} 14 \mathrm{~A}}\right)$. However, the minor residual activity of POSH observed when ALIX-Gag interaction was blocked by the $\triangle \mathrm{YP}$ mutation in the L-domain containing p6 Gag protein might indicate that POSH also regulates another factor along the pathway that mediates virus release. This together with the fact that siRNA-mediated knockdown of POSH fails to block the function of ALIX raises the question of whether the cooperative function of POSH and ALIX in terms of promoting virus release is a result of a direct interaction between both proteins, or a consequence of an independent positive role of POSH-mediated ubiquitination somewhere else in the pathway. The observation that POSH, which by itself does not interact detectably with Gag, ubiquitinates ALIX is consistent with a model whereby the binding of Gag to ALIX meditates virus egress while POSH acts as an auxiliary factor. Since downregulation of POSH has no detectable influence on the function of ALIX, it is either that $\mathrm{POSH}$ is not strictly required or that the POSH function can be substituted by another E3-ligase. Similar to Tsg101, which is also substrate for two different E3 ligases, namely 


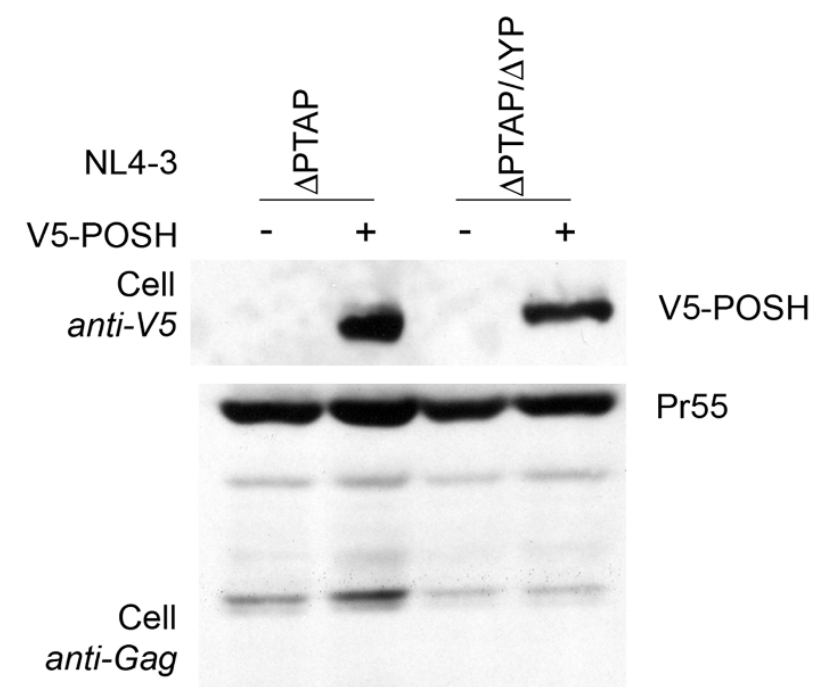

CA
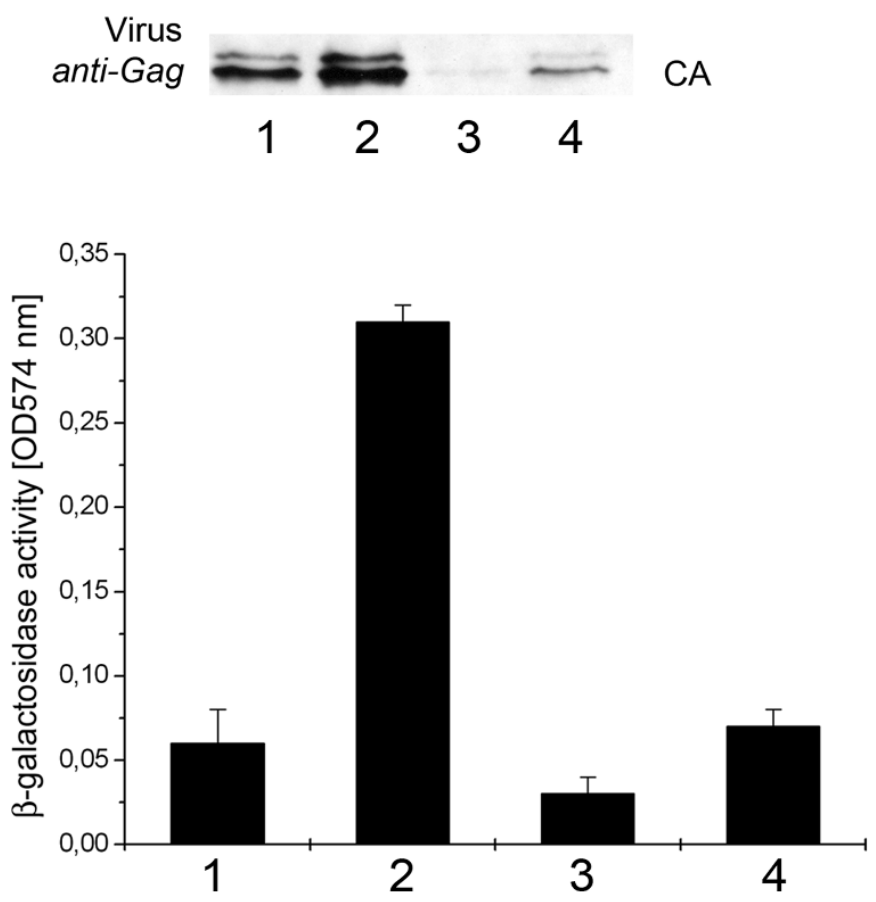

\section{Figure 6}

POSH mediated enhancement of virus release requires a functional ALIX binding site in Gag. Virus release, Gag processing, and exogenous expression of POSH were analyzed by Western blot (upper panel). Amount of infectious units released from the cells was analyzed by $\beta$-galactosidase quantification after infection of TZM-bl cells (lower panel). Shown are infectivities relative to the HIV-I ${ }_{\triangle P T A P}$ control \pm SD. Lane I shows HIV-I ${ }_{\triangle P T A P}$ mutant co-transfected with the empty PCDNA3. IV5His control vector, lane 2 shows HIV-I $\Delta_{\text {PTAP }}$ mutant co-transfected with a V5-POSH expression plasmid, lanes 3 and 4 show the HIV-I ${ }_{\triangle \mathrm{PTAP} / \Delta \mathrm{YP}}$ double mutant co-transfected with the empty control plasmid and the vector expressing V5POSH, respectively. 
Tal (Tsg101 associated ligase) and Mahogunin [33,34], ALIX may be ubiquitinated by an additional E3 ligase, when POSH is downregulated.

Until now, the molecular mechanism by which ALIX supports virus release is unresolved. Apparently, it requires the interaction of the N-terminal Bro-domain of ALIX with the ESCRT-III component CHMP4B as mutations in ALIX that prevent ALIX/ESCRT-III interaction abolish the ability of ALIX to rescue HIV-1 L-domain mutants $[9,10]$. In addition, the C-terminal PRR of ALIX was shown to be essential for virus release $[9,10]$, however, the nature of this activity is currently unknown. Furthermore, as ALIX fulfills several distinct cellular functions, it is possible that ubiquitination by POSH regulates a function that is redundant for virus release. That the ubiquitination of ALIX by POSH might not be essential for virus release is supported by the results that show lack of correlation between the requirement for ALIX ubiquitination and for the capacity of ALIX to support virus release. For example, ALIX truncation mutants that cannot promote virus release such as the $\triangle B$ ro and the $\triangle P R R$ are similarly ubiquitinated and both ubiquitination patterns are similar to that of native ALIX.

Previous studies implicated POSH as a regulator of Gag transport from the TGN to the cell membrane, a function that precedes ESCRT-mediated virus budding from the membrane. The function of POSH mediated ubiquitination of ALIX may accelerate a step of Gag transport prior to the virus assembly at the cell membrane. As the ratelimiting step of virus production of HIV- $1_{\triangle \mathrm{PTAP}}$ mutant virions is the ESCRT-dependent release of virus particles from the cell membrane, inhibition of steps earlier in the pathway would not show a significant phenotype as long as enough Gag is transported to the cell membrane.

However, besides its role in ESCRT, ALIX was initially identified as interaction partner of ALG-2, a calcium binding protein that is necessary for induction of apoptosis $[35,36]$. The observation that POSH binds both, ALIX and ALG-2 in a calcium dependent manner [23] together with the implicated role of POSH in the induction of apoptosis and neuronal differentiation [37-39] suggest a functional role for POSH and ALIX in the regulation of apoptosis and calcium metabolism. Further evidence for this hypothesis comes from findings that POSH regulates calcium homeostasis through spatial control of HERP [22]. The fact, that ALIX links ALG-2 and ESCRT pathways [40] might indicate that these pathways are somehow connected and are utilized by HIV-1.

It has been reported that actin polymerisation is essential for Gag transport of EIAV to the plasma membrane and the subsequent disassembly of actin filaments facilitates virus budding and virion release from the cell membrane
[41]. ALIX, that contains actin and alpha actinin binding sites, also plays a pivotal role in actin organisation. Pan and colleagues reported that ALIX expression in a fibroblast cell line was required to maintain actin-based structures such as stress fibers and lamellipodia [42].

We have no evidence for direct interaction between POSH and actin. Nevertheless, considering the interaction between POSH and ALIX, the actin interaction properties of ALIX and the requirement for actin dynamics for virus production and release, we propose (a model) whereby both proteins cooperate at the plasma membrane where ALIX serves a dual function: it bridges between Gag and actin through respective binding sites while it recruits ESCRT to initiate virus budding. POSH may regulate disassembly of actin from Gag, possibly through ubiquitination of ALIX, thereby facilitating detachment of nascent virus particles from the cell membrane.

The model is consistent with the absolute requirement for ALIX as it is essential for mutant virus budding. Likewise, the model is in agreement with overexpression of $\mathrm{POSH}$ enhancing virus release possibly by increasing the rate of actin disassembly.

Finally, it should to be considered that POSH also interacts with another ESCRT-associated protein as it was shown to ubiquitinate Hrs, which in contrast to ALIX, is subsequently targeted for proteasomal degradation. Hrs interacts with the ESCRT-I components Tsg101 and HCRP1/Vps37A and C-terminal fragments of Hrs that interact with Tsg101 interfere with HIV-1 particle production [43]. Thus, it has to be considered that overexpression as well as downregulation of POSH may also regulate HIV-1 release distant to the hereby described POSH-ALIX interaction and overlapping effects may account for the partial nature of the phenotype described.

\section{Conclusion}

We have identified ALIX as an ubiquitination substrate of POSH and indicate that both proteins are involved in the process of $\mathrm{YPX}_{n} \mathrm{~L}$-dependent HIV-1 release. However, while ALIX is obligatory for the release of HIV-1 L-domain mutant viruses, POSH, albeit rate-limiting, may be functionally interchangeable for the function of ALIX.

\section{Methods}

\section{Plasmids and siRNA}

The HIV-1 $1_{\triangle \mathrm{PTAP}}$ mutant is based on the HIV-1 molecular clone NL4-3 [44] in which the 7PTAP10 L-domain motif was replaced by ${ }^{7} \mathrm{LIRL}^{10}$ without affecting the overlapping pol-reading frame [27]. In the HIV-1 $1_{\triangle \mathrm{PTAP} / \Delta \mathrm{YP}}$, in addition

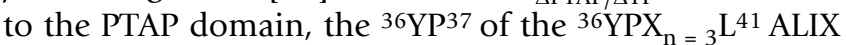
binding motif in $\mathrm{p} 6$ was mutated to ${ }^{36} \mathrm{SR}^{37}$ by site directed mutagenesis, without affecting the overlapping pol-reading frame. Plasmids pcDNA3.1-POSH-V5-His and 


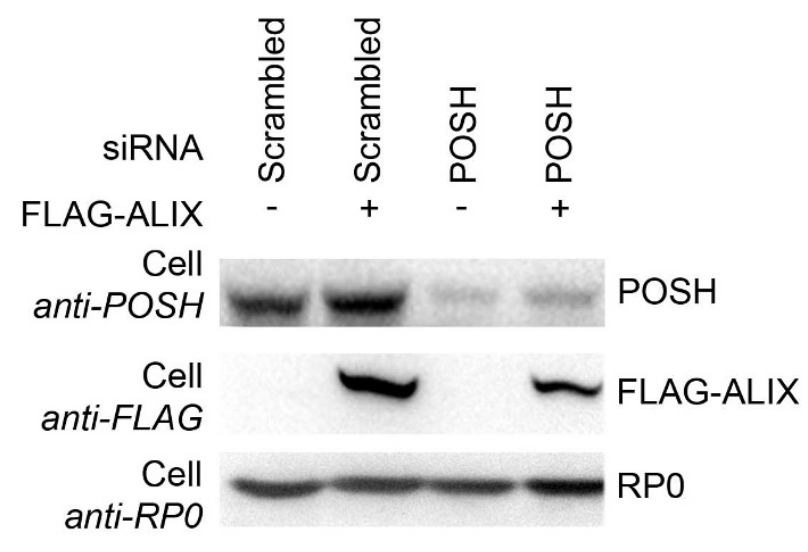

$\operatorname{Pr} 55$

Cell

anti-Gag
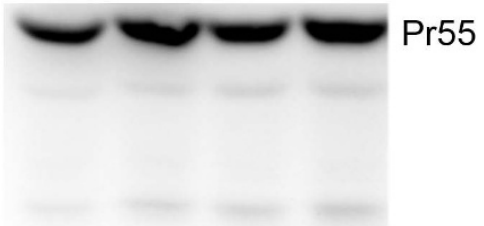

thenti-Gag
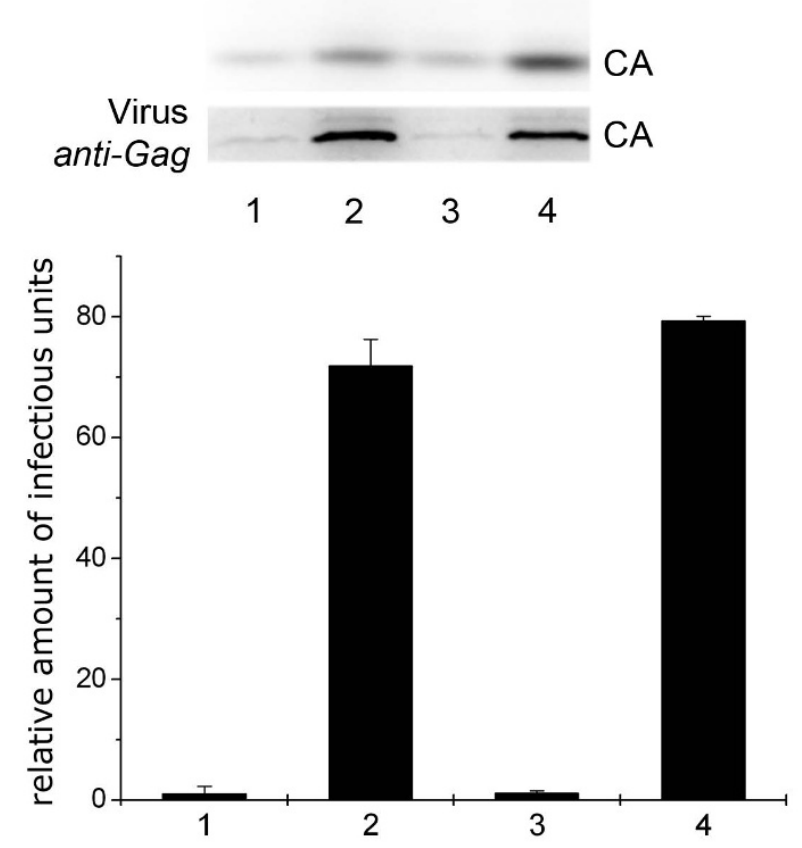

Figure 7

ALIX mediated rescue of HIV-I L-domain mutant occurs independently of POSH. Endogenous levels of POSH were knocked down by RNAi in order to determine, whether ALIX can enhance virus release in the absence of POSH. HIV$\mathrm{I}_{\triangle P T A P}$ was co-transfected with a control siRNA together with either an empty plasmid or an ALIX expression plasmid (lanes I and 2 respectively). HIV-I ${ }_{\triangle P T A P}$ was co-transfected with a POSH specific siRNA and either an empty plasmid or an ALIX expression plasmid (lanes 3 and 4 respectively). RPO: ribosomal PO antigen. 
pcDNA3.1-POSH-V14A-V5-His were described previously [19]. Plasmids containing ALIX cDNA were derived from IMAGE clone IMAGE: 4340998. For expression in mammalian cells, the 5' region of the cDNA was PCR amplified in frame with either T7 tag or a FLAG tag peptide sequence, and ligated back into the same plasmid to create pCMV-T7-ALIX and pCMV-FLAG-ALIX. For bacterial expression FLAG-ALIX or a region containing residues 200-320 were cloned into pGEX-6P (GE Healthcare). To the full-length ALIX an N-terminal six histidine tag was also added. The short interfering RNA (siRNA) against POSH was described in [19]. The H310A cell line that stably express POSH-specific short hairpin (sh)RNA was previously described [22].

\section{Production of recombinant ALIX}

For expression of recombinant full-length ALIX, GSTFLAG-ALIX-6xHIS was induced with IPTG at $22^{\circ} \mathrm{C}$ for $3 \mathrm{~h}$. Protein was purified by glutathione chromatography dialyzed into $20 \mathrm{mM}$ Tris- $\mathrm{HCl} \mathrm{pH} \mathrm{7.6,} 100 \mathrm{mM} \mathrm{NaCl}, 20 \mathrm{mM}$ Imidazole, $10 \mathrm{mM} \beta$-mercaptoethanol and further purified by Ni-NTA (Qiagen) chromatography and further dialyzed into $20 \mathrm{mM}$ Tris $\mathrm{pH}$ 7.6, $1 \mathrm{mM}$ DTT, $0.5 \mathrm{mg} / \mathrm{ml}$ ovalbumin.

\section{Antibodies}

Antibodies against FLAG and V5 were obtained from Sigma and Invitrogen, respectively. Ubiquitin monoclonal antibody FK2 was from mouse anti-POSH monoclonal antibody was previously described [22]. The human anti-HIV-1 Gag antiserum was provided by the AIDS Research and Reference Reagent Program. For antiALIX sera preparation GST-ALIX (200-320) was expressed in E. coli BL21 by IPTG induction. Protein was purified from cell lysate by glutathione chromatography and the GST moiety removed by digestion with PreScission protease (GE Healthcare). The isolated polypeptide was used to raise antibodies in rabbits (Sigma-Aldrich, Israel).

\section{Cell culture}

HEK-293T, HeLa SS6, H310A, H314A [22], and TZM-bl cells were cultured in Dulbecco's modified Eagle's medium (DMEM) supplemented with 10\% inactivated fetal calf serum (FCS), $2 \mathrm{mM}$ L-glutamine, $100 \mathrm{U} / \mathrm{ml}$ penicillin and $100 \mu \mathrm{g} / \mathrm{ml}$ streptomycin. H314A and H310A cells were cultured in the same medium but additionally supplemented with $0.5 \mathrm{mg} / \mathrm{ml}$ hygromycin Jurkat T-cells were maintained in RPMI 1640 supplemented with $10 \%$ inactivated FCS, $2 \mathrm{mM} \mathrm{L-glutamine,} \mathrm{and} 100 \mathrm{U} / \mathrm{ml}$ penicillin and $100 \mu \mathrm{g} / \mathrm{ml}$ streptomycin.

\section{In vitro ALIX ubiquitin conjugation assays}

Recombinant ALIX: Purified recombinant ALIX (50 ng) was incubated with $50 \mathrm{nM}$ of recombinant $\mathrm{E} 1,0.3 \mu \mathrm{M}$ of $\mathrm{UbcH5c}$ or Ubc13/Uev1a (where indicated), $13 \mathrm{nM}$ of bacterially expressed maltose-binding protein (MBP)POSH [19] in a final volume of $25 \mu \mathrm{l}$ containing $40 \mathrm{mM}$ Tris-HCl pH 7.5, $1 \mathrm{mM}$ DTT, $2 \mathrm{mM}$ ATP, $5 \mathrm{mM} \mathrm{MgCl}_{2}, 5$ $\times 10^{-3}(\mathrm{vol} / \mathrm{vol})$ Tween 20 and $2 \mu \mathrm{g}$ ubiquitin. After incubation for $45 \mathrm{~min}$ at $30^{\circ} \mathrm{C}$, ALIX was isolated via immunoprecipitation. The ALIX immune complexes were washed in a buffer containing $0.6 \%$ SDS (to dissociate $\mathrm{POSH}$ ) and ubiquitin conjugation was subsequently detected by Western blot with anti-ubiquitin (FK2).

Cell-expressed ALIX: $3 \mu \mathrm{g}$ of T7-tagged ALIX or ALIX truncation mutants expressing plasmids (as indicated in the figure legends) were transfected each into HEK-293 cells $\left(5.4 \times 10^{6}\right.$ cells per $10 \mathrm{~cm}$ dish). One day after the transfection, ALIX was immunoprecipitated with anti-T7 and protein G beads. One third of the ALIX beads packed volume was transferred into a fresh tube and subsequently incubated in an in vitro ubiquitination reaction as described above. ALIX ubiquitination was detected by western blot analysis with anti-ubiquitin as described above.

\section{In vivo $A L I X$ ubiquitination}

HeLa SS6 cells or H310 cells $\left(9 \times 10^{5}\right.$ cells in a 6 -well plate) were transfected with T7-ALIX plasmid $(0.5 \mu \mathrm{g})$ and V5-POSH $(1 \mu \mathrm{g})$ or V5-POSH V14A $(0.2 \mu \mathrm{g})$ and HAtagged ubiquitin $(1 \mu \mathrm{g})$. The day after the transfection ALIX was isolated by immunoprecipitation with anti-T7. Ubiquitination of ALIX was detected by Western blot analysis of the ALIX immune complexes with anti-HA.

\section{ALIX-POSH binding assays}

Interaction in cells: FLAG-tagged ALIX $(3 \mu \mathrm{g})$ and V5POSH $(6 \mu \mathrm{g})$ or V5-POSH V14A $(1.2 \mu \mathrm{g})$ were coexpressed in HEK 293 cells. One day after the transfection cells were extracted in lysis buffer containing $10 \mathrm{mM}$ Tris $\mathrm{HCl} \mathrm{pH} \mathrm{7.5,} 150 \mathrm{mM} \mathrm{NaCl}, 5 \mathrm{mM} \mathrm{MgCl}$ and $1 \%$ Octyl $\beta$ D-glucopyranoside (Ultrol grade, Calbiochem). ALIX was isolated by immunoprecipitation with anti-FLAG beads. The beads were washed three times with lysis buffer and subsequently resolved in a $7.5 \%$ SDS gel. ALIX-bound POSH was detected by Western blot analysis with anti-V5.

Interaction between bacterially-expressed ALIX and POSH: Bacterially expressed GST-Flag-ALIX and POSH (50 ng each) were incubated in lysis buffer as described above. After incubation for at $30^{\circ} \mathrm{C}$ for $45 \mathrm{~min}$. ALIX was isolated by immunoprecipitation as described above. The ALIX beads were washed three times with lysis buffer and then subjected to Western blot analysis with anti-POSH (PT1).

\section{Virus release and infectivity assays}

HeLa SS6, H310A and H314A cells $\left(9 \times 10^{5}\right.$ cells/well in 6 -well plates) were transfected with $1 \mu \mathrm{g}$ of HIV- $1_{\triangle \mathrm{PTAP}}$ 
plasmid together with $0.2 \mu \mathrm{g}$ of ALIX expression vector, 1 $\mu \mathrm{g}$ POSH expression vector and $0.2 \mu \mathrm{g} \mathrm{POSH}^{\mathrm{V} 14 \mathrm{~A}}$ expression vector per well. DNA content was adjusted to $4 \mu \mathrm{g}$ total DNA by addition of empty pcDNA3.1V5His and transfection was carried out with $10 \mu \mathrm{l}$ Lipofectamine ${ }^{\mathrm{TM}}$ 2000 (Invitrogen) per well according to manufacturer's instructions. For RNAi HeLa SS6 $\left(2 \times 10^{5}\right.$ cells/well $)$ cells were initially transfected with siRNA using Lipofectamine $^{\mathrm{TM}} 2000$ according to manufacturer instructions and split the next day. $48 \mathrm{~h}$ after the initial transfection, cells were co-transfected with another portion (one fourth of first transfection) of siRNA together with plasmids encoding ALIX $(0.1 \mu \mathrm{g})$, POSH $(1 \mu \mathrm{g}), \mathrm{V} 14 \mathrm{~A}(0.2 \mu \mathrm{g})$ and HIV- $1_{\triangle \mathrm{PTAP}}(1 \mu \mathrm{g})$. Cells and virions were harvested $24 \mathrm{~h}$ post transfection. Proteins were extracted by RIPA $(1 \%$ NP-40, 0.5\% Na-DOC, 0.1\% SDS, $0.15 \mathrm{M} \mathrm{NaCl} ; 50 \mathrm{mM}$ Tris-HCl pH 7.4; 5 mM EDTA) lysis and analyzed by Western blotting. Cell debris from virus containing supernatant was removed by centrifuging at $1000 \times g$ for $5 \mathrm{~min}$ and $8000 \times g$ for $10 \mathrm{~min}$. Virions were subsequently pelleted over $20 \%$ sucrose at $20000 \times g$ for $90 \mathrm{~min}$, re-suspended in $1 \mathrm{ml}$ of PBS, pelleted again for $20000 \times g$ for 90 min to remove serum albumins and finally analyzed by Western blotting. HIV-1-infectious titers were assayed by single round infection of Hela TZM-bl cells. 4000 cells per well in 96 well plate were infected by overnight incubation with prepared virus supernatants in a total volume of $100 \mu \mathrm{l}$ in the presence of $10 \mu \mathrm{g} / \mathrm{ml}$ polybrene. To avoid spread of infection, cells were washed and dextran-sulfate $(100 \mu \mathrm{g} / \mathrm{ml})$ was added $16 \mathrm{~h}$ post infection. Three days post infection, cells were lysed in $40 \mu \mathrm{l}$ CAT lysis buffer (Roche) and $\beta$-galactosidase activity was determined. Therefore, cell $35 \mu \mathrm{l}$ of the cell lysate were added to $215 \mu \mathrm{l}$ Z buffer pH $7.0\left(60 \mathrm{mM} \mathrm{Na}_{2} \mathrm{HPO}_{4} ; 40 \mathrm{mM} \mathrm{NaH} \mathrm{PO}_{4} ; 10\right.$ $\mathrm{mM} \mathrm{KCl} ; 10 \mathrm{mM} \mathrm{MgSO}$; $0.05 \mathrm{mM} \beta$-mercaptoethanol; $0,08 \%$ SDS) containing $0.375 \mathrm{mg}$ chlorophenolred $\beta$-Dgalactopyranoside (Roche), incubated at room temperature $1-8 \mathrm{~h}$ and read at $574 \mathrm{~nm}$.

\section{Authors' contributions}

YR initiated the project and US initiated and supervised the infectious experiments. OF and EY carried out binding and ubiquitination experiments. DT supervised the molecular biology-associated work. OE contributed important scientific insight. JV analyzed virus release experiments assisted by TW and SS in many procedures. NB did the electron microscopy (data not shown). JV and YR wrote the manuscript.

\section{Acknowledgements}

This work was supported by a grant IE-S08T06 from the German Human Genome Research Project, and by grants SFB 643-AI, from the German Research Council to US. We thank Gudrun Holland for excellent technical assistance.

\section{References}

I. Bieniasz PD: Late budding domains and host proteins in enveloped virus release. Virology 2006, 344:55-63.

2. von Schwedler UK, Stuchell M, Muller B, Ward DM, Chung HY, Morita E, Wang HE, Davis T, He GP, Cimbora DM, et al.: The protein network of HIV budding. Cell 2003, I I 4:70 I-7I3.

3. Martin-Serrano J: The Role of Ubiquitin in Retroviral Egress. Traffic 2007, 8: 1297-I303.

4. Martin-Serrano J, Zang T, Bieniasz PD: HIV-I and Ebola virus encode small peptide motifs that recruit TsgIOI to sites of particle assembly to facilitate egress. Nat Med 200I, 7:1313-1319.

5. Hurley JH: ESCRT complexes and the biogenesis of multivesicular bodies. Curr Opin Cell Biol 2008, 20:4-II.

6. Hurley JH, Emr SD: The ESCRT complexes: structure and mechanism of a membrane-trafficking network. Annu Rev Biophys Biomol Struct 2006, 35:277-298.

7. Williams RL, Urbe S: The emerging shape of the ESCRT machinery. Nat Rev Mol Cell Biol 2007, 8:355-368.

8. Strack B, Calistri A, Craig S, Popova E, Göttlinger HG: AIPI/ALIX is a binding partner for HIV-I p6 and EIAV p9 functioning in virus budding. Cell 2003, I I4:689-699.

9. Fisher RD, Chung HY, Zhai Q, Robinson H, Sundquist WI, Hill CP: Structural and biochemical studies of ALIXIAIPI and its role in retrovirus budding. Cell 2007, I 28:84|-852.

10. Usami Y, Popov S, Göttlinger HG: Potent rescue of human immunodeficiency virus type I late domain mutants by ALIX/AIPI depends on its CHMP4 binding site. J Virol 2007, 8I:6614-6622.

II. Freed EO: Viral late domains. J Virol 2002, 76:4679-4687.

12. Langelier C, von Schwedler UK, Fisher RD, De Domenico I, White PL, Hill CP, Kaplan J, Ward D, Sundquist WI: Human ESCRT-II complex and its role in human immunodeficiency virus type I release. J Virol 2006, 80:9465-9480.

13. Munshi UM, Kim J, Nagashima K, Hurley JH, Freed EO: An Alix fragment potently inhibits HIV-I budding: characterization of binding to retroviral YPXL late domains. J Biol Chem 2007, 282:3847-3855.

14. Zhai Q, Fisher RD, Chung HY, Myszka DG, Sundquist WI, Hill CP: Structural and functional studies of ALIX interactions with YPX $_{\mathrm{n}} \mathrm{L}$ late domains of HIV-I and EIAV. Nat Struct Mol Biol 2008, I5:43-49.

15. VerPlank L, Bouamr F, LaGrassa TJ, Agresta B, Kikonyogo A, Leis J, Carter CA: TsgI0I, a homologue of ubiquitin-conjugating (E2) enzymes, binds the L domain in HIV type I Pr55Gag. Proc Natl Acad Sci USA 200I, 98:7724-7729.

16. Garrus JE, von Schwedler UK, Pornillos OW, Morham SG, Zavitz KH, Wang HE, Wettstein DA, Stray KM, Cote M, Rich RL, et al.: Tsg 10 I and the vacuolar protein sorting pathway are essential for HIV-I budding. Cell 200I, 107:55-65.

17. Demirov DG, Orenstein JM, Freed EO: The late domain of human immunodeficiency virus type I p6 promotes virus release in a cell type-dependent manner. J Virol 2002, 76:105-117.

18. Popov S, Popova E, Inoue M, Göttlinger HG: Human immunodeficiency virus type I Gag engages the Brol domain of ALIX/ AIP I through the nucleocapsid. J Virol 2008, 82: I 389-1398.

19. Alroy I, Tuvia S, Greener T, Gordon D, Barr HM, Taglicht D, MandilLevin R, Ben-Avraham D, Konforty D, Nir A, et al:: The trans-Golgi network-associated human ubiquitin-protein ligase POSH is essential for HIV type I production. Proc Natl Acad Sci USA 2005, 102: 1478-I483.

20. Kim GH, Park E, Kong YY, Han JK: Novel function of POSH, a JNK scaffold, as an E3 ubiquitin ligase for the Hrs stability on early endosomes. Cell Signal 2006, I 8:553-563.

21. Tsuda M, Langmann C, Harden N, Aigaki T: The RING-finger scaffold protein Plenty of SH3s targets TAKI to control immunity signalling in Drosophila. EMBO Rep 2005, 6:1082-1087.

22. Tuvia S, Taglicht D, Erez O, Alroy I, Alchanati I, Bicoviski V, DoriBachash M, Ben-Avraham D, Reiss $Y$ : The ubiquitin E3 ligase POSH regulates calcium homeostasis through spatial control of Herp. J Cell Biol 2007, 177:5I-6I.

23. Tsuda M, Seong KH, Aigaki T: POSH, a scaffold protein for JNK signaling, binds to ALG-2 and ALIX in Drosophila. FEBS Lett 2006, 580:3296-3300. 
24. Hofmann RM, Pickart CM: In vitro assembly and recognition of Lys-63 polyubiquitin chains. J Biol Chem 200I, 276:27936-27943.

25. Pickart CM: Mechanisms underlying ubiquitination. Annu Rev Biochem 200I, 70:503-533.

26. Odorizzi G: The multiple personalities of Alix. J Cell Sci 2006, I 1 9:3025-3032.

27. Huang $M$, Orenstein JM, Martin MA, Freed EO: $\mathbf{p}^{6} \mathrm{Gag}$ is required for particle production from full-length human immunodeficiency virus type I molecular clones expressing protease. I Virol 1995, 69:6810-6818.

28. Dikic I: ALIX-ing phospholipids with endosome biogenesis. Bioessays 2004, 26:604-607.

29. Carlton JG, Martin-Serrano J: Parallels between cytokinesis and retroviral budding: a role for the ESCRT machinery. Science 2007, 316: | 1908-1912

30. Carlton JG, Agromayor M, Martin-Serrano J: Differential requirements for Alix and ESCRT-III in cytokinesis and HIV-I release. Proc Natl Acad Sci USA 2008, 105: 1054 |-I0546.

31. Schmidt MH, Dikic I, Bogler O: Src phosphorylation of Alix/AIP I modulates its interaction with binding partners and antagonizes its activities. J Biol Chem 2005, 280:34|4-3425.

32. Kim HT, Kim KP, Lledias F, Kisselev AF, Scaglione KM, Skowyra D, Gygi SP, Goldberg AL: Certain pairs of ubiquitin-conjugating enzymes (E2s) and ubiquitin-protein ligases (E3s) synthesize nondegradable forked ubiquitin chains containing all possible isopeptide linkages. I Biol Chem 2007, 282: I7375-I7386.

33. Amit I, Yakir L, Katz M, Zwang Y, Marmor MD, Citri A, Shtiegman K, Alroy I, Tuvia S, Reiss Y, et al.: Tal, a Tsg I OI-specific E3 ubiquitin ligase, regulates receptor endocytosis and retrovirus budding. Genes Dev 2004, I8:1737-1752.

34. Kim BY, Olzmann JA, Barsh GS, Chin LS, Li L: Spongiform neurodegeneration-associated E3 ligase Mahogunin ubiquitylates TSGIOI and regulates endosomal trafficking. Mol Biol Cell 2007, 18: I 29-1|142.

35. Missotten M, Nichols A, Rieger K, Sadoul R: Alix, a novel mouse protein undergoing calcium-dependent interaction with the apoptosis-linked-gene 2 (ALG-2) protein. Cell Death Differ 1999, 6: 124-129.

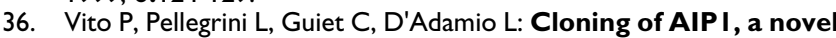
protein that associates with the apoptosis-linked gene ALG2 in a Ca2+-dependent reaction. J Biol Chem 1999, 274: I533-1540.

37. Xu Z, Kukekov NV, Greene LA: POSH acts as a scaffold for a multiprotein complex that mediates JNK activation in apoptosis. Embo / 2003, 22:252-26I.

38. Kim GH, Park E, Han JK: The assembly of POSH-JNK regulates Xenopus anterior neural development. Dev Biol 2005, 286:256-269.

39. Zhang QG, Wang RM, Yin XH, Pan J, Xu TL, Zhang GY: Knockdown of $\mathrm{POSH}$ expression is neuroprotective through downregulating activation of the MLK3-MKK4-JNK pathway following cerebral ischaemia in the rat hippocampal CAI subfield. I Neurochem 2005, 95:784-795.

40. Mahul-Mellier AL, Hemming FJ, Blot B, Fraboulet S, Sadoul R: Alix, making a link between apoptosis-linked gene-2, the endosomal sorting complexes required for transport, and neuronal death in vivo. J Neurosci 2006, 26:542-549.

41. Chen C, Weisz OA, Stolz DB, Watkins SC, Montelaro RC: Differential effects of actin cytoskeleton dynamics on equine infectious anemia virus particle production. J Virol 2004, 78:882-89I.

42. Pan S, Wang R, Zhou X, He G, Koomen J, Kobayashi R, Sun L, Corvera J, Gallick GE, Kuang J: Involvement of the conserved adaptor protein Alix in actin cytoskeleton assembly. J Biol Chem 2006, 28 I:34640-34650

43. Bouamr F, Houck-Loomis BR, De Los Santos M, Casaday RJ, Johnson MC, Goff SP: The C-terminal portion of the Hrs protein interacts with TsgIOI and interferes with human immunodeficiency virus type I Gag particle production. J Virol 2007, 81:2909-2922.

44. Adachi A, Gendelman HE, Koenig S, Folks T, Willey R, Rabson A, Martin MA: Production of acquired immunodeficiency syndromeassociated retrovirus in human and nonhuman cells transfected with an infectious molecular clone. I Virol 1986, 59:284-291.
Publish with Biomed Central and every scientist can read your work free of charge

"BioMed Central will be the most significant development for disseminating the results of biomedical research in our lifetime. "

Sir Paul Nurse, Cancer Research UK

Your research papers will be:

- available free of charge to the entire biomedical community

- peer reviewed and published immediately upon acceptance

- cited in PubMed and archived on PubMed Central

- yours - you keep the copyright
BioMedcentral 